\title{
The impact of global warming on seasonality of ocean primary production
}

\author{
S. Henson ${ }^{1, *}$, H. Cole ${ }^{2}$, C. Beaulieu ${ }^{3}$, and A. Yool ${ }^{1}$ \\ ${ }^{1}$ National Oceanography Centre, European Way, Southampton, UK \\ ${ }^{2}$ Ocean and Earth Sciences, University of Southampton, European Way, Southampton, UK \\ ${ }^{3}$ Atmospheric and Oceanic Sciences, Princeton University, Princeton, NJ, USA \\ * Invited contribution by S. Henson, recipient of the EGU Arne Richter Award for Outstanding Young Scientists 2012.
}

Correspondence to: S. Henson (s.henson@noc.ac.uk)

Received: 3 January 2013 - Published in Biogeosciences Discuss.: 29 January 2013

Revised: 23 April 2013 - Accepted: 10 May 2013 - Published: 28 June 2013

\begin{abstract}
The seasonal cycle (i.e. phenology) of oceanic primary production (PP) is expected to change in response to climate warming. Here, we use output from 6 global biogeochemical models to examine the response in the seasonal amplitude of PP and timing of peak PP to the IPCC AR5 warming scenario. We also investigate whether trends in PP phenology may be more rapidly detectable than trends in annual mean PP. The seasonal amplitude of PP decreases by an average of $1-2 \%$ per year by 2100 in most biomes, with the exception of the Arctic which sees an increase of $\sim 1 \%$ per year. This is accompanied by an advance in the timing of peak PP by $\sim 0.5-1$ months by 2100 over much of the globe, and particularly pronounced in the Arctic. These changes are driven by an increase in seasonal amplitude of sea surface temperature (where the maxima get hotter faster than the minima) and a decrease in the seasonal amplitude of the mixed layer depth and surface nitrate concentration. Our results indicate a transformation of currently strongly seasonal (bloom forming) regions, typically found at high latitudes, into weakly seasonal (non-bloom) regions, characteristic of contemporary subtropical conditions. On average, $36 \mathrm{yr}$ of data are needed to detect a climate-changedriven trend in the seasonal amplitude of PP, compared to $32 \mathrm{yr}$ for mean annual PP. Monthly resolution model output is found to be inadequate for resolving phenological changes. We conclude that analysis of phytoplankton seasonality is not necessarily a shortcut to detecting climate change impacts on ocean productivity.
\end{abstract}

\section{Introduction}

Climate change is expected to alter the seasonal cycle of oceanic primary productivity by changing the availability of nutrients and light. The effects may include shifts in the timing of the start, end or peak of the growing season, in addition to changes in the amplitude of the seasonal cycle. Understanding the phenology (i.e. the timing of annually recurring events) in phytoplankton is important to characterising variability in higher trophic levels, $\mathrm{CO}_{2}$ fluxes and oceanic carbon export and sequestration. Changes to phytoplankton phenology are likely to have knock-on effects for higher trophic levels via the "match-mismatch" hypothesis (Cushing, 1990), as late blooms may result in a reduced period of time when prey (phytoplankton) are available to predators (zooplankton or larval fish), and vice versa for earlier blooms. In the northwest Atlantic, for example, the survival of haddock larvae is closely linked to the timing of phytoplankton bloom initiation (Platt et al., 2003), and it has also been suggested that the annual shrimp hatching has evolved to coincide with the mean bloom start date (Koeller et al., 2009). Changes to the seasonality of primary production may also impact oceanic carbon export and storage (Lutz et al., 2007), as regions with large amplitude seasonal cycles, e.g. high latitudes, are typically regions of high productivity, with blooms dominated by large, rapidly sinking diatoms. Future changes in seasonality therefore imply changes to export production and alteration of the food web. 
Although the change in seasonal timing of temperature is faster in the oceans than on land (Burrows et al., 2011), there are fewer reports of long-term trends in plankton phenology, likely due to the relative shortness of marine ecosystem time series. In terrestrial ecosystems, the response to warmer temperatures has been observed as earlier first flowering and a longer growing season in boreal and temperate regions, resulting in higher primary productivity (Myneni et al., 1997; Walther et al., 2002). Earlier breeding or emergence has also been observed in amphibians, birds and butterflies, particularly at higher latitudes (Parmesan, 2007), which has resulted in mismatches between, for example, winter moth egg hatch and budburst on oak trees that act as larval hosts. A few long time series of marine ecosystems exist, such as the long-running Continuous Plankton Recorder dataset, which indicates that in the North Sea spring occurrences of phyto- and zooplankton are shifting earlier (Edwards and Richardson, 2004), with phytoplankton peak timing advancing by $\sim 0.3$ days/decade between 1976 and 2005. Time series stations, such as the Bermuda Atlantic Time Series, also provide sufficiently long data records to show that the timing of peak zooplankton abundance has advanced by $\sim 2-3$ weeks over the last $15 \mathrm{yr}$ (Steinberg et al., 2012). These regional studies of plankton phenology are complemented by global-scale analyses conducted using satellite ocean colour data. Generally, these show that the timing of phytoplankton bloom initiation progresses polewards through winter and early spring in subpolar to subtropical latitudes (Racault et al., 2012), whilst oligotrophic regions show very weak seasonality (Cole et al., 2012). Substantial interannual variability in phytoplankton phenology is also evident (e.g. Henson et al., 2009; Platt et al., 2009; Sasaoka et al., 2011; Zhai et al., 2011; Thomalla et al., 2011; Kahru et al., 2011; Racault et al., 2011; Sapiano et al., 2012).

Current patterns of phytoplankton phenology are set partly by the population's response to nutrient and light availability. At high latitudes, deep winter mixing results in light limitation of phytoplankton growth but at the same time ensures a plentiful supply of nutrients, so that shoaling of the mixed layer in spring results in rapid, sustained growth, i.e. a strong seasonal cycle. This is in contrast to subtropical regions where mixed layers are sufficiently shallow year-round such that light limitation does not occur. However, this lack of mixing results in nutrient limitation through much of the spring and summer, and phytoplankton blooms are only stimulated when winter mixing or storms deepen the mixed layer sufficiently to entrain new nutrients, resulting in a weak seasonal cycle. Even weaker (indeed, non-existent) seasonality is found in oligotrophic regions where persistent stratification leads to chronic nutrient limitation, and only small, sporadic increases in phytoplankton abundance occur, with no annual repeating cycle. In this context, continued global warming, leading to increased stratification, is hypothesised to reduce the seasonal magnitude of ocean primary production in nutrient-limited regions, but may advance the phy- toplankton growth season in light-limited regions (due to earlier alleviation of light limitation) and result in stronger blooms (Bopp et al., 2001; Doney, 2006). The regions of weak seasonality, e.g. oligotrophic gyres, are expected to expand (Polovina et al., 2011), reducing the amplitude of the seasonal cycle along gyre boundaries.

Phytoplankton seasonality is highly responsive to altered forcing (Ji et al., 2010), due to rapid phytoplankton growth rates and sensitivity to changes in environmental conditions. It has therefore been suggested that "phenology is the most responsive aspect of nature to warming" (Sparks and Menzel, 2002). Here, we examine the possibility that global warming may be more readily detectable in phenological markers than in other metrics, using output from 6 biogeochemical models run for the IPCC CMIP5 project (Taylor et al., 2012) to examine how the timing of peak production and the amplitude of the seasonal cycle respond to climate change up to the year 2100. We also investigate the length of time series needed to distinguish global warming signals in phytoplankton seasonality from the natural variability. An earlier study (Henson et al., 2010) suggested that $\sim 30-40 \mathrm{yr}$ of continuous data is needed to separate a global warming trend in primary production (PP) from the natural variability. Here, we investigate whether climate-change-driven trends are detectable more rapidly in PP seasonality than in PP itself.

\section{Methods}

The coupled climate model output is taken primarily from the Coupled Model Intercomparison Project Phase 5 (CMIP5) multimodel archive, available from http://cmip-pcmdi.llnl. gov/cmip5/data_portal.html. An exception is the National Oceanography Centre (NOC) model that instead used model output from an ocean-only General Circulation Model (GCM) driven by atmospheric forcing derived from a separate CMIP5 simulation (using the UKMO's HadGEM2-ES model). Table 1 presents a full list of the models used. Projections were forced with the Representative Concentration Pathway 8.5 (RCP8.5) scenario (Moss et al., 2010) in which emissions continue to rise, resulting in a warming potential from all greenhouse gases of $8.5 \mathrm{~W} \mathrm{~m}^{-2}$ by 2100 . All model output analysed here is at monthly resolution from January 2006-December 2098. The variables used are vertically integrated primary production by all phytoplankton types (referenced as "intpp" in the CMIP5 database), mixed layer depth (MLD) defined by the model's mixing scheme (omlmax), surface nitrate concentration (no3), sea surface temperature (tos) and dissolved iron concentration (dfe).

As seasonality metrics we use the amplitude of the seasonal cycle, defined as the maximum minus the minimum value in a given year, and the month of peak productivity. Note that the "year" runs from July-June in the Southern Hemisphere and January-December in the Northern Hemisphere. The historical model output is initially compared to 
Table 1. List of models used in this study and relevant references for the biogeochemical component of the models.

\begin{tabular}{|c|c|c|}
\hline Institute and abbreviation used here & Model & Reference \\
\hline $\begin{array}{l}\text { Canadian Centre for Climate Modelling } \\
\text { and Analysis (CCCMA) }\end{array}$ & CanESM2 & Zahariev et al. (2008) \\
\hline $\begin{array}{l}\text { NOAA Geophysical Fluid Dynamics } \\
\text { Laboratory (GFDL) }\end{array}$ & GFDL-ESM2M & $\begin{array}{l}\text { Sarmiento et al. (2010), } \\
\text { the Supplement therein }\end{array}$ \\
\hline Met Office Hadley Centre (Hadley) & HadGEM2-CC & Collins et al. (2011) \\
\hline Institut Pierre Simon Laplace (IPSL) & IPSL-CM5A-MR & Seferian et al. (2013) \\
\hline Max Planck Institute (MPI) & MPI-ESM-LR & $\begin{array}{l}\text { http://www.mpimet.mpg. } \\
\text { de/fileadmin/models/ } \\
\text { MPIOM/HAMOCC5. } \\
\text { 1_TECHNICAL_REPORT.pdf }\end{array}$ \\
\hline National Oceanography Centre (NOC) & NEMO-MEDUSA & Yool et al. (2011) \\
\hline
\end{tabular}

contemporary observations of seasonality metrics. Satellitederived primary production data were estimated using the Vertically Generalized Production Model (VGPM) applied to SeaWiFS data covering the period January 1998 to December 2005 at monthly, $9 \mathrm{~km}$ resolution (Behrenfeld and Falkowski, 1997) and regridded onto the coarser resolution model grids. Although the satellite-derived PP fields themselves have errors potentially as large as biogeochemical models (Friedrichs et al., 2009; Saba et al., 2010), they provide an indication of the large-scale features in PP seasonality. A period of $20 \mathrm{yr}$ (January 1985 to December 2005) at monthly resolution was used to fully resolve long-term means. Natural variability cycles should occur at a similar frequency in the models as they do in the real world but the phase (timing) of the cycles may differ. Using a long period to identify mean values reduces the likelihood of out of phase cycles causing discrepancies between observations and model output (Schneider et al., 2008).

Trends are calculated using generalized least squares by fitting the model

$y_{t}=\mu+\omega t+N_{t}$,

where $y_{t}$ is the data at time $t, \mu$ is the intercept, $\omega$ is the trend magnitude and $N_{t}$ represents the residual noise at time $t$. We assume that the noise follows a first-order autoregressive process, $\operatorname{AR}(1)$, expressed as

$N_{t}=\phi N_{t-1}+\varepsilon_{t}$,

where $\phi$ is the first-order autocorrelation and $\varepsilon_{t}$ are independent and identically normally distributed random errors with a mean of zero and constant variance. We use a first-order autoregressive process to represent the autocorrelation in the data, since it is typically used as a rough approximation of the internal variability of the climate system (Hasselmann,
1976). A higher-order autoregressive process may occasionally better represent the noise in some models and some regions. However, there was no consistent pattern to which models and regions suggested a higher-order autocorrelation, so in the interest of parsimony we apply the AR(1) model at all times. Similarly, the underlying assumptions of normality and constant variance of the residuals were not always respected in every grid cell, suggesting that a data transformation be applied, or that a linear trend is not appropriate. We tried a logarithmic transformation which did not improve the fit, and we therefore use linear trends in the interest of parsimony.

The number of years of data, $n^{*}$, required to distinguish a trend from natural variability is calculated by the method of Weatherhead et al. (1998), with a probability of detection of $90 \%$ and a confidence level of $95 \%$ :

$n^{*}=\left[\frac{3.3 \sigma_{N}}{|\omega|} \sqrt{\frac{1+\varphi}{1-\varphi}}\right]^{2 / 3}$,

where $\sigma_{N}$ is the standard deviation of the noise (residuals after trend has been removed). Model output is divided into biomes intended to represent large-scale biogeographical provinces, defined as in Henson et al. (2010) which separates light-limited and equatorial regions on the basis of incident irradiance, MLD and net heat flux.

\section{Results}

\subsection{Modelled and satellite-derived PP seasonality}

A visual comparison shows that the models broadly reproduce the spatial patterns of the satellite-derived PP in both the seasonal amplitude and timing of peak PP reasonably well 


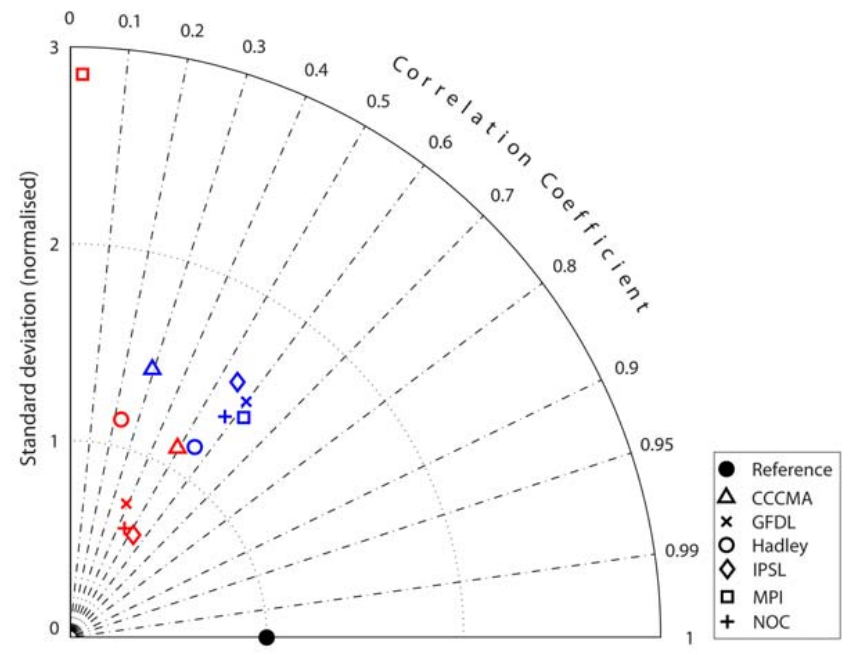

Fig. 1. Taylor diagram showing model-data comparison of global spatial variability in seasonal amplitude of PP (red) and timing of peak PP (blue) for 6 models. Model hindcast runs averaged from 1985-2005 are compared with satellite-derived data averaged from 1998-2007. Taylor diagrams compare the correlation coefficient of the data and model and the normalised model standard deviation (model standard deviation/data standard deviation). A perfect model has a correlation coefficient of 1 and normalised standard deviation of 1 (indicated by the black reference circle).

(see Supplement, Figs. S1 and S2). In the satellite-derived PP, the North Atlantic, parts of the North Pacific, the Subtropical Front region of the Southern Ocean and some subtropical coastal regions are shown to have large seasonal amplitudes in primary production $\left(\sim 1000-3000 \mathrm{mgC} \mathrm{m}^{-2}\right.$ day $^{-1}$ ), whereas the oligotrophic gyres have the smallest amplitudes $\left(<500 \mathrm{mgC} \mathrm{m}^{-2} \mathrm{day}^{-1}\right)$. There are some noticeable discrepancies in some of the models. The Hadley and MPI models both overestimate the seasonal amplitude of PP in the Southern Ocean, whilst the CCCMA model overestimates the seasonal amplitude in the eastern Pacific upwelling region. In addition, the seasonal amplitude in the North Atlantic is underestimated in both the Hadley and NOC models. All models broadly capture the spatial pattern in peak PP timing, which occurs in the Northern Hemisphere during February/March at low latitudes, progressing through to July/August at higher latitudes. In the Southern Hemisphere peak PP occurs at low latitudes during September/October, advancing through to January/February at high latitudes.

The agreement in the spatial patterns between the model output and satellite-derived PP can be summarised using Taylor diagrams (Taylor, 2001; Fig. 1). Taylor diagrams display the correlation coefficient of the data and model and the normalised model standard deviation (model standard deviation/data standard deviation). A perfect model has both a correlation coefficient and normalised standard deviation of 1 . If the normalised standard deviation is 1 , then the spatial variability in the model output matches that of the observations.
Table 2. Comparison of model-derived seasonality metrics (hindcast runs, mean of 1985-2005) with those observed in satellitederived primary production (mean 1998-2007). All correlations (Pearson correlation coefficient) are significant at the $99 \%$ level.

\begin{tabular}{lcccc}
\hline Model & \multicolumn{2}{c}{ Seasonal amplitude of PP } & \multicolumn{2}{c}{ Timing of peak PP } \\
\hline & $\begin{array}{c}\text { Standard } \\
\text { deviation }\end{array}$ & $\begin{array}{c}\text { Correlation } \\
\text { coefficient }\end{array}$ & $\begin{array}{c}\text { Standard } \\
\text { deviation }\end{array}$ & $\begin{array}{c}\text { Correlation } \\
\text { coefficient }\end{array}$ \\
\hline CCCMA & 1.11 & 0.49 & 1.42 & 0.29 \\
GFDL & 0.74 & 0.39 & 1.50 & 0.60 \\
Hadley & 1.14 & 0.23 & 1.16 & 0.55 \\
IPSL & 0.61 & 0.53 & 1.55 & 0.55 \\
MPI & 2.86 & 0.02 & 1.42 & 0.62 \\
NOC & 1.38 & 0.45 & 0.61 & 0.57 \\
\hline
\end{tabular}

In general, the Taylor diagrams show that most of the models compare well to the satellite-derived PP for both parameters. The correlation coefficients range from 0.02 to 0.53 for the seasonal amplitude and from 0.29 to 0.62 for the month of peak primary production (Table 2). The spatial variability in the timing of peak PP is consistently overestimated (i.e. greater than 1) with the standard deviation ranging from 1.16 to 1.55 , whereas the spatial variability in seasonal amplitude is seen to be both under- and overestimated (standard deviation ranges from $0.61-2.86$ ) across the range of models. Weak agreement between the satellite-derived and modelled seasonal amplitude generally arises due to an overestimate of PP seasonal amplitude in the Southern Ocean. Taylor diagrams excluding the region south of $50^{\circ} \mathrm{S}$ generally show improved agreement with the data (Supplement, Fig. S3).

Most of the models show good agreement with satellitederived estimates of the timing of peak PP (Fig. 1) with relatively high correlation coefficients (0.55-0.62), although the spatial variability is generally overestimated. Overall, the modelled timing of peak PP more closely resembles the observations than modelled seasonal amplitude. There is no model that stands out as being the best or the worst in comparison to observations, and in some cases a model will simulate one seasonality metric better than the other. Broadly, the models reproduce the satellite-derived PP spatial pattern well, and so taken together should provide a reasonable estimate of the trends in future projections.

\subsection{Trends in seasonality}

The trend in mean annual PP for 2006-2098 is shown in Fig. 2. The majority of models show a decrease in PP over much of the global ocean, with the exception of parts of the Southern Ocean and Arctic, which have an increasing trend. The corresponding trend in the seasonal amplitude of PP is shown in Fig. 3. In general, the amplitude of the seasonal cycle decreases in low and midlatitudes and increases in the Southern Ocean and Arctic. Expansion of the oligotrophic gyres is reflected in the bands of decreased seasonal amplitude at the gyre boundaries and around the Pacific 

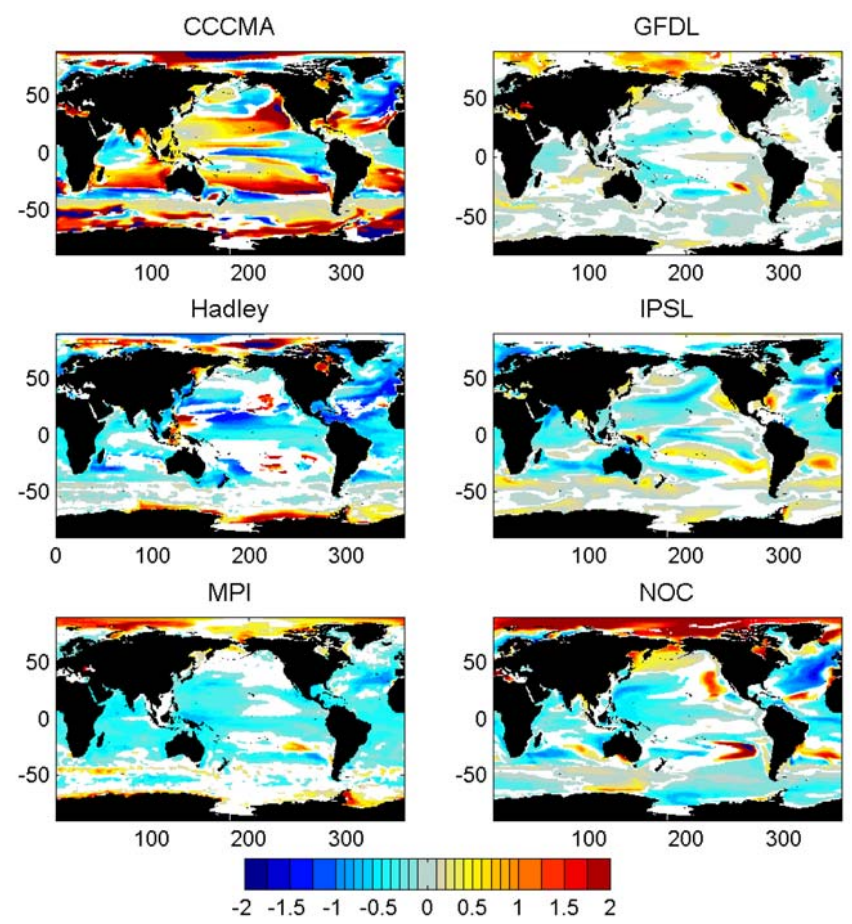

Fig. 2. Trends in mean annual PP for 2006-2100 (expressed as average $\%$ change per year) for 6 models forced with IPCC AR5 scenario RCP8.5. Only points where the trend is statistically significant at the $95 \%$ level are plotted.

equatorial upwelling region. However, in some models increased seasonal amplitude is seen beyond the outer edge of the oligotrophic gyres, i.e. in a band south of the gyre edge in the Southern Ocean, northwest of the North Pacific and North Atlantic gyres and equatorward of the gyre boundary in the Pacific upwelling region. A consistent increase in the seasonal amplitude of PP is found in the Arctic and parts of the Southern Ocean, particularly in the vicinity of the Antarctic land mass.

The difference in the timing of peak PP between the average of 2006-2026 and 2081-2100 is plotted in Fig. 4. Differences are reported because the monthly resolution discretises the time series to the extent that calculating trends is unreliable. Generally, peak PP advances by $0.5-1$ months by 2098 over much of the globe, with the exception of along the expanding edge of the oligotrophic gyre where peak PP is $1-2$ months later (particularly pronounced in the IPSL model). In oligotrophic regions, there is currently a very weak or completely absent seasonal cycle due to perennial nutrient limitation. As the gyres expand, subtropical regions which had previously been seasonally nutrient limited may become oligotrophic. As well as a reduction in PP, the amplitude of the seasonal cycle is predicted to decrease. Mid- to high latitudes which were previously seasonally light limited have strong seasonal cycles, typically peaking in spring. With continued warming, light limitation may be alleviated by reduced mix-

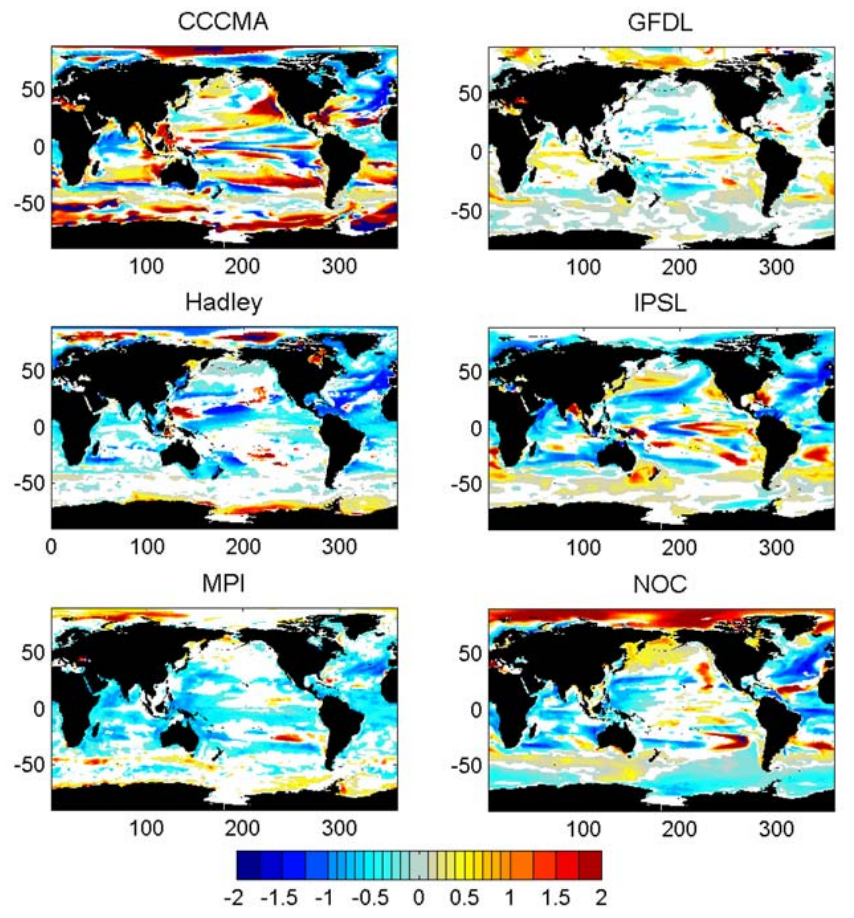

Fig. 3. Trends in PP seasonal amplitude for 2006-2100 (expressed as average $\%$ change per year) for 6 models forced with IPCC AR5 scenario RCP8.5. Only points where the trend is statistically significant at the $95 \%$ level are plotted.

ing, but PP then becomes more rapidly nutrient limited, as seen by a decrease in seasonal amplitude and shift to earlier peak PP. This reflects a change from a subpolar-type spring bloom to a subtropical-type autumn bloom (e.g. as observed in the contemporary North Atlantic in response to the North Atlantic Oscillation by Henson et al., 2009, 2012). In the North Atlantic, for example, where PP is typically seasonally light limited due to deep winter mixing, total PP decreases dramatically, as does the magnitude of the seasonal cycle, with the peak PP occurring earlier.

In the Southern Ocean, PP is both seasonally light and iron limited. In parts of the Southern Ocean, this results in a strong seasonal cycle with a spring peak, while in others chronic iron limitation results in almost oligotrophic conditions (i.e. weak seasonality). By 2098, the model results suggest increased seasonal amplitude in PP in a band south of the oligotrophic gyre boundary and in the Ross and Weddell seas. A similar response of increased amplitude and earlier PP peaks (by $\sim 0.5-2$ months) is seen in the Arctic, likely due to increased melting of sea ice and thus earlier alleviation of light limitation.

The biome mean trends in PP and seasonal amplitude of PP, as well as the difference in timing of peak PP, are shown in Fig. 5. The range in the model estimates is represented by the error bars. Despite intermodel differences in predicted trends, some general patterns emerge. Biome mean 

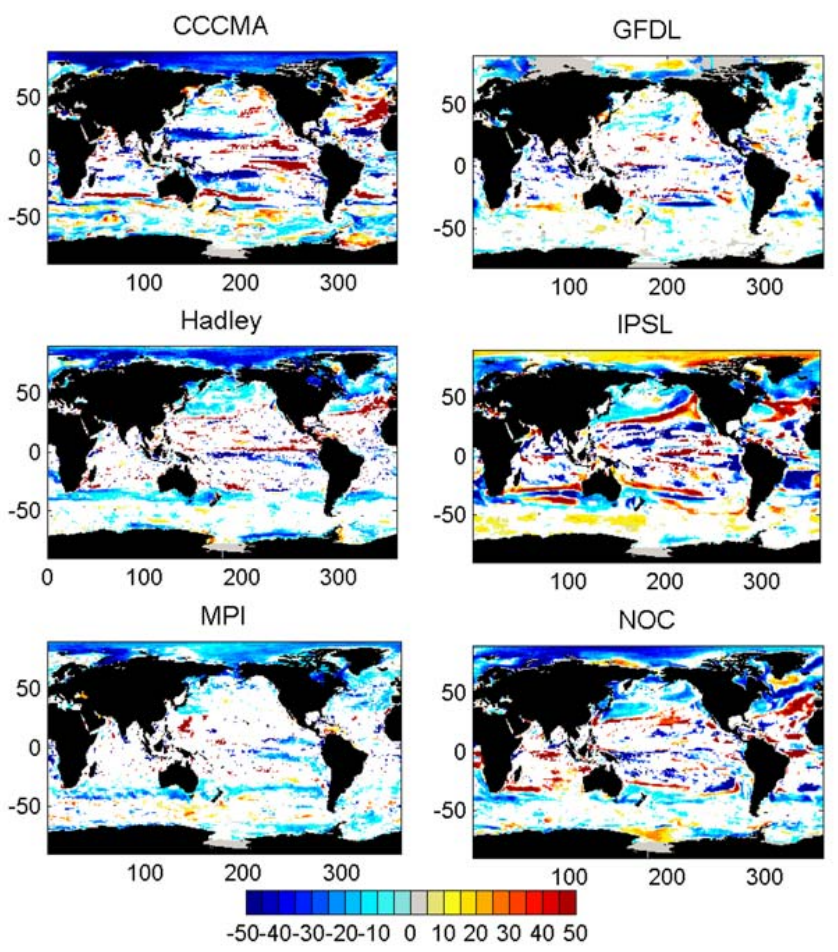

Fig. 4. Difference in timing of peak PP between the period 20062026 and 2081-2100 (where negative values indicate earlier peak timing). Only points where a 1-way ANOVA analysis showed no significant difference in the means of the 2 periods (significance at $5 \%$ level) are plotted.

PP decreases everywhere by an average change per year of $0.1-0.3 \%$ except in the Arctic, where PP increases by an average of $\sim 0.2 \%$ per year. The seasonal amplitude of PP decreases by an average of $0.2-0.4 \%$ per year in a majority of biomes, excluding the Southern Ocean regions and the Arctic where it increases by an average of $0.05-0.1 \%$ per year. The timing of peak PP shifts earlier by 2-10 days, with the exception of the oligotrophic North Pacific, North Atlantic and Indian biomes, which show later peaks of 2-5 days.

\subsection{Drivers of change in seasonal cycles}

Changes in the seasonal amplitude of PP are likely to be driven by changes in the seasonal amplitude of drivers such as MLD or nutrient supply. In all biomes and all models, sea surface temperature (SST) increases by an average of $\sim 0.03-0.05^{\circ} \mathrm{C}$ per year, i.e. an increase of $3-5^{\circ} \mathrm{C}$ between 2000 and 2100 (Fig. 6a). However, there is not only an increase in the mean annual SST. The seasonal amplitude of SST also increases in most biomes, particularly the Arctic (Fig. 6b). This is a result of peak annual SST increasing at a faster rate than the minimum annual SST, i.e. the highs are getting hotter more rapidly than the lows.

Increased SST is reflected in shallower mean annual MLD (Fig. 6c), particularly pronounced in the Pacific and Atlantic sectors of the Southern Ocean and the high-latitude North Atlantic. The seasonal amplitude of MLD also decreases by an average of $\sim 0.1 \%$ per year, except in the high latitudes where the average percent change per year is 4-5\% (Fig. 6d). The effect of decreased seasonal amplitude in MLD on surface nitrate concentrations is evident in Fig. 6e, which shows decreasing nitrate of $\sim 0.05 \%$ per year, with the exception of the equatorial Atlantic and Bay of Bengal which exhibit increased nitrate concentrations, despite shallower MLD. This is possibly due to changes in wind-driven upwelling not reflected in the mean annual MLD. The seasonal amplitude in nitrate concentration also decreases in the majority of biomes and models (Fig. 6f), likely due to reduced winter mixing.

Unlike the situation with the macronutrient nitrate (Fig. 4e), there are trends towards higher surface dissolved iron concentrations across all biomes (Fig. 4g). These are typically stronger in regions where iron is supplied by aeolian dust, and lower (to near zero) in regions, such as the Southern Ocean and equatorial Pacific, where aeolian dust supply is limited. Note that none of the models include timevariant atmospheric dust deposition, so any increase in surface iron is not a consequence of increased desertification. In the case of dust-affected regions, since the seasonal amplitude of vertical mixing broadly decreases in response to climate change, macronutrient supply from deep, nutrientrich waters also declines. As a result, production declines in these regions, and the iron deposited via dust is unable to be utilised by phytoplankton and so accumulates. As such, what might appear a potential source of enhanced growth - extra iron - cannot support enhanced PP. By contrast, in iron-limited high-nutrient, low-chlorophyll regions such as the Southern Ocean, the supply of nitrate and iron is largely from below, so this decoupling of surface nutrient availability is absent. These results emphasise the importance of the processes by which nutrients, macro- and micro-, are supplied to the surface ocean.

\subsection{Detection of trends in PP seasonality}

We examine the hypothesis that global-warming-driven trends may be more rapidly detectable in PP seasonality than in PP itself by comparing the length of time series required to detect trends in both the amplitude of the PP seasonal cycle and mean annual PP. We use the method of Weatherhead et al. (1998), which estimates the number of years of data needed to distinguish a trend from the background variability (Eq. 3). This approach was applied previously in Henson et al. (2010) to annual mean PP from models forced with the IPCC A2 scenario (Nakicenovic and Swart, 2000). Here, we update these estimates using the IPCC AR5 RCP8.5 scenario (Moss et al., 2010). Per Rogelj et al. (2012), the temperature impact of RCP8.5 is slightly greater than that of SRES scenario A2, and more closely resembles that of SRES scenario A1F1, although it is slightly less extreme than this latter scenario. 
Table 3. Number of years of continuous data needed to detect a climate-change-driven trend above natural variability in primary production and the seasonal amplitude of primary production (bold) reported for each model as the average within the biome. One standard deviation of the spatial average is shown in parentheses.

\begin{tabular}{|c|c|c|c|c|c|c|c|}
\hline Biome/Model & СCCMA & GFDL & Hadley & IPSL & MPI & NOC & $\begin{array}{l}\text { Biome } \\
\text { mean }\end{array}$ \\
\hline \multirow{2}{*}{ High-latitude North Pacific } & $35(13)$ & $37(11)$ & $34(10)$ & $36(10)$ & $45(8)$ & $19(12)$ & 34 \\
\hline & $35(12)$ & $46(7)$ & 38 (8) & $31(10)$ & $46(8)$ & $25(10)$ & 37 \\
\hline \multirow[t]{2}{*}{ Oligotrophic North Pacific } & $19(12)$ & $46(7)$ & 37 (9) & $28(10)$ & $33(8)$ & $33(9)$ & 33 \\
\hline & 33 (11) & $47(8)$ & $38(9)$ & $34(10)$ & $43(8)$ & $38(9)$ & 39 \\
\hline \multirow[t]{2}{*}{ Equatorial Pacific } & $35(8)$ & $34(11)$ & 31 (7) & $34(9)$ & $35(8)$ & $27(10)$ & 33 \\
\hline & $38(9)$ & $40(9)$ & $38(9)$ & $34(9)$ & $37(9)$ & $37(9)$ & 37 \\
\hline \multirow[t]{2}{*}{ Oligotrophic South Pacific } & $22(11)$ & $38(11)$ & $42(9)$ & $34(11)$ & $37(9)$ & $36(10)$ & 35 \\
\hline & $32(11)$ & $42(9)$ & $42(9)$ & $36(10)$ & $38(8)$ & $38(9)$ & 38 \\
\hline \multirow[t]{2}{*}{ Southern Ocean - Pacific } & $28(11)$ & $34(11)$ & $39(11)$ & $33(12)$ & $44(8)$ & $24(10)$ & 34 \\
\hline & $34(10)$ & $39(10)$ & $39(12)$ & $38(12)$ & $44(8)$ & $26(10)$ & 37 \\
\hline \multirow{2}{*}{ High-latitude North Atlantic } & $31(10)$ & $36(9)$ & $26(10)$ & $31(9)$ & $33(11)$ & $24(10)$ & 30 \\
\hline & $31(10)$ & $35(8)$ & $29(10)$ & $31(9)$ & $38(9)$ & 30 (9) & 32 \\
\hline \multirow[t]{2}{*}{ Oligotrophic North Atlantic } & $26(13)$ & $42(12)$ & $29(10)$ & $28(10)$ & $25(10)$ & $34(9)$ & 31 \\
\hline & $36(11)$ & $45(10)$ & $33(9)$ & $33(10)$ & $32(10)$ & $37(9)$ & 36 \\
\hline \multirow[t]{2}{*}{ Equatorial Atlantic } & $25(10)$ & $42(8)$ & $17(6)$ & $17(2)$ & $20(4)$ & $18(6)$ & 23 \\
\hline & $25(10)$ & $43(9)$ & $26(7)$ & $23(10)$ & $25(8)$ & $22(7)$ & 27 \\
\hline \multirow[t]{2}{*}{ Oligotrophic South Atlantic } & $19(10)$ & $36(11)$ & $36(12)$ & $20(11)$ & $26(9)$ & $34(10)$ & 28 \\
\hline & $29(10)$ & $36(10)$ & $39(11)$ & $27(10)$ & $34(10)$ & $38(10)$ & 34 \\
\hline \multirow[t]{2}{*}{ Southern Ocean - Atlantic } & $26(10)$ & $34(14)$ & $38(10)$ & $27(13)$ & $41(8)$ & $24(11)$ & 32 \\
\hline & $28(8)$ & $36(12)$ & $40(10)$ & $34(12)$ & $44(7)$ & $26(11)$ & 35 \\
\hline \multirow[t]{2}{*}{ Arabian Sea } & $40(8)$ & $35(8)$ & $32(10)$ & $18(4)$ & $29(5)$ & $29(8)$ & 30 \\
\hline & $38(8)$ & $41(7)$ & $40(8)$ & 33 (11) & $30(7)$ & 32 (9) & 36 \\
\hline \multirow[t]{2}{*}{ Bay of Bengal } & $40(10)$ & $41(8)$ & $38(10)$ & $24(9)$ & $27(7)$ & $29(10)$ & 33 \\
\hline & $38(9)$ & $47(5)$ & $40(8)$ & $32(9)$ & $33(8)$ & $32(9)$ & 37 \\
\hline \multirow[t]{2}{*}{ Oligotrophic Indian Ocean } & $17(11)$ & $45(8)$ & $42(10)$ & $27(12)$ & $35(7)$ & $36(11)$ & 34 \\
\hline & $29(10)$ & $44(8)$ & $43(10)$ & $27(12)$ & $44(8)$ & $40(11)$ & 38 \\
\hline \multirow[t]{2}{*}{ Southern Ocean - Indian } & $28(10)$ & $36(10)$ & $38(10)$ & $29(12)$ & $41(8)$ & $27(10)$ & 33 \\
\hline & $32(9)$ & $38(10)$ & $43(12)$ & $36(10)$ & $45(7)$ & 27 (9) & 37 \\
\hline \multirow[t]{2}{*}{ Arctic Ocean } & $27(11)$ & $31(8)$ & $40(9)$ & $40(14)$ & $35(9)$ & $28(8)$ & 34 \\
\hline & $29(10)$ & $34(8)$ & $40(8)$ & $30(12)$ & $44(7)$ & $25(8)$ & 34 \\
\hline
\end{tabular}

For the amplitude of the seasonal cycle in PP, the number of years required to detect a global warming trend is plotted in Fig. 7b. In some regions, and some models, time series as short as $\sim 20-25$ yr may be adequate, but in the majority $30-40 \mathrm{yr}$ of data are needed. The biome median values are reported in Table 3 and show that trends in the seasonal amplitude of PP should be detectable most rapidly in the equatorial Atlantic and high-latitude North Atlantic (27 and $32 \mathrm{yr}$, respectively). Trends in the seasonal amplitude of PP take the longest to detect above the background variability in oligotrophic regions ( $\sim 38 \mathrm{yr})$.

The number of years of data needed to detect a global warming trend in annual mean PP is also displayed in Table 3 and Fig. 7a. In most biomes, a trend in annual mean PP is detectable more rapidly than a trend in the seasonal amplitude of PP. However, averaged over all models and biomes, the number of years of data required to detect a trend is similar for annual mean PP (mean $32 \pm 3 \mathrm{yr}$ ) and the seasonal amplitude of PP (mean $36 \pm 3 \mathrm{yr}$ ). This suggests that natural interannual and decadal variability in PP seasonality is similarly strong as for annual mean PP and therefore that climate change cannot be detected in the metrics of seasonality tested here more rapidly than from PP itself.

\section{Discussion}

\subsection{Response of phytoplankton seasonality to climate change}

The seasonal cycle of PP responds strongly to climate change. The weak seasonal cycles in PP typical of lowlatitude, oligotrophic regions in the contemporary ocean expand poleward. Regions which currently exhibit pronounced seasonality have increasingly reduced seasonal amplitude, and the timing of peak PP shifts earlier, from spring towards late winter - signs of their transition from typical highlatitude spring bloom to non-blooming tropical conditions. The Arctic is the only region in which the seasonal amplitude of PP consistently increases.

These patterns are driven by the decrease in seasonal amplitude of MLD and subsequent decline in surface nitrate availability. High-latitude regions which exhibit substantial seasonality are characterised by low PP during winter when deep mixing imposes light limitation, followed by a strong spring bloom as the mixed layer shoals. The pronounced seasonal cycle is thus driven by deep winter mixing, which ensures both seasonal light limitation and a plentiful supply of 

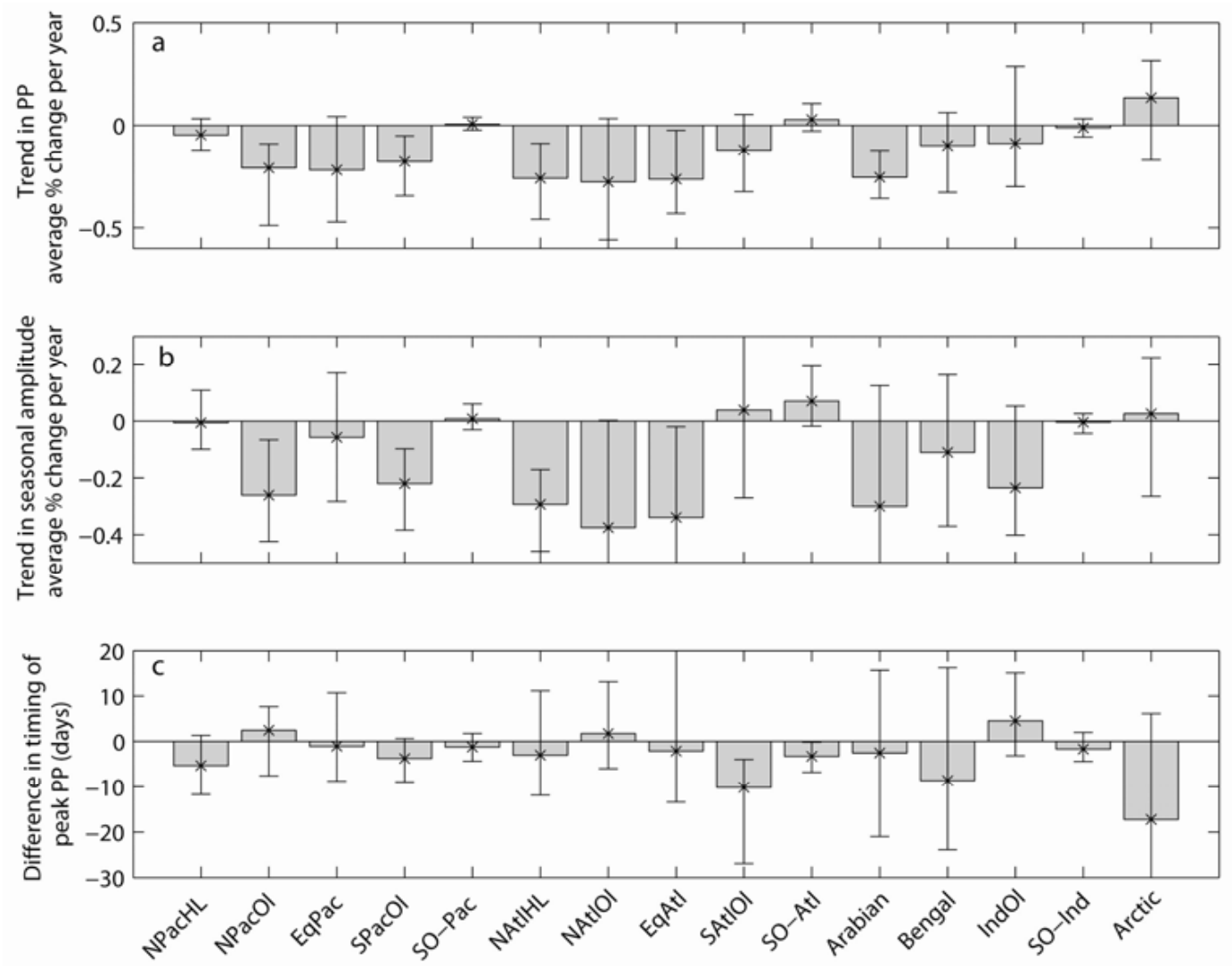

Fig. 5. Biome mean trends and standard deviations for 6 models forced with IPCC AR5 scenario RCP8.5 until 2100. (a) Primary production (PP), (b) seasonal amplitude of PP and (c) timing of peak PP (where negative values indicate earlier timing of peak PP). Biome labels indicate (left to right) high-latitude North Pacific, oligotrophic North Pacific, equatorial Pacific, oligotrophic South Pacific, Southern Ocean Pacific, high-latitude North Atlantic, oligotrophic North Atlantic, equatorial Atlantic, oligotrophic South Atlantic, Southern Ocean - Atlantic, Arabian Sea, Bay of Bengal, oligotrophic Indian Ocean, Southern Ocean - Indian, and Arctic Ocean (see Henson et al., 2010, for biome definitions).

entrained nutrients to fuel the spring bloom. Reduced winter mixing, by as much as $40-60 \%$ by 2100 in some highlatitude regions (Fig. 6c), extends the potential growing season by alleviating light limitation earlier in the year, but also restricts entrainment of new nutrients. This is also reflected in a shift forward of peak PP (Fig. 5c), indicating a transition from subpolar, spring bloom to subtropical conditions, where the bloom tends to occur in autumn or early winter as nutrient limitation is alleviated during mixed layer deepening, while the relatively shallow winter MLD ensures light is not limiting (Henson et al., 2009). Climate change has been hypothesised to have a positive impact on PP in light-limited regions due to a reduction in mixing, leading to earlier alleviation of light limitation and hence a longer growing season (e.g. Doney, 2006; Sarmiento et al., 2004). However, our results suggest that by 2100 the potential benefits of extending the growing season length are outweighed by the negative effects of nutrient limitation, resulting in a transformation of previously high PP bloom regions into nutrient-limited, low $\mathrm{PP}$, non-seasonal conditions.
The effect of expanding oligotrophic gyres is particularly pronounced in the high-latitude North Atlantic, the classic spring bloom region. Here, in the transition zone between the subpolar and subtropical gyres, interannual to decadal-scale shifts from subpolar- to subtropical-type blooms has been observed in response to changes in the phase of the North Atlantic Oscillation (Henson et al., 2009, 2012). Whether the currently observed relationships between natural interannual to decadal variability can be regarded as analogues of the future response to climate change has been questioned (e.g. Stone et al., 2001). However, here there is a suggestion that the response of PP to contemporary variability does seem to mirror the longer-term climate-change-driven trend.

In the Arctic and some parts of the Southern Ocean, PP and the seasonal amplitude of PP increase. The Arctic experiences the strongest warming trend (Fig. 6a) and, on average, a $20 \%$ increase in PP between 2006 and 2100. In the Arctic, reduced mixing results in reduced nutrient supply via vertical entrainment; however, the predominant effect appears to be the expansion of a seasonally ice-free area in which a 

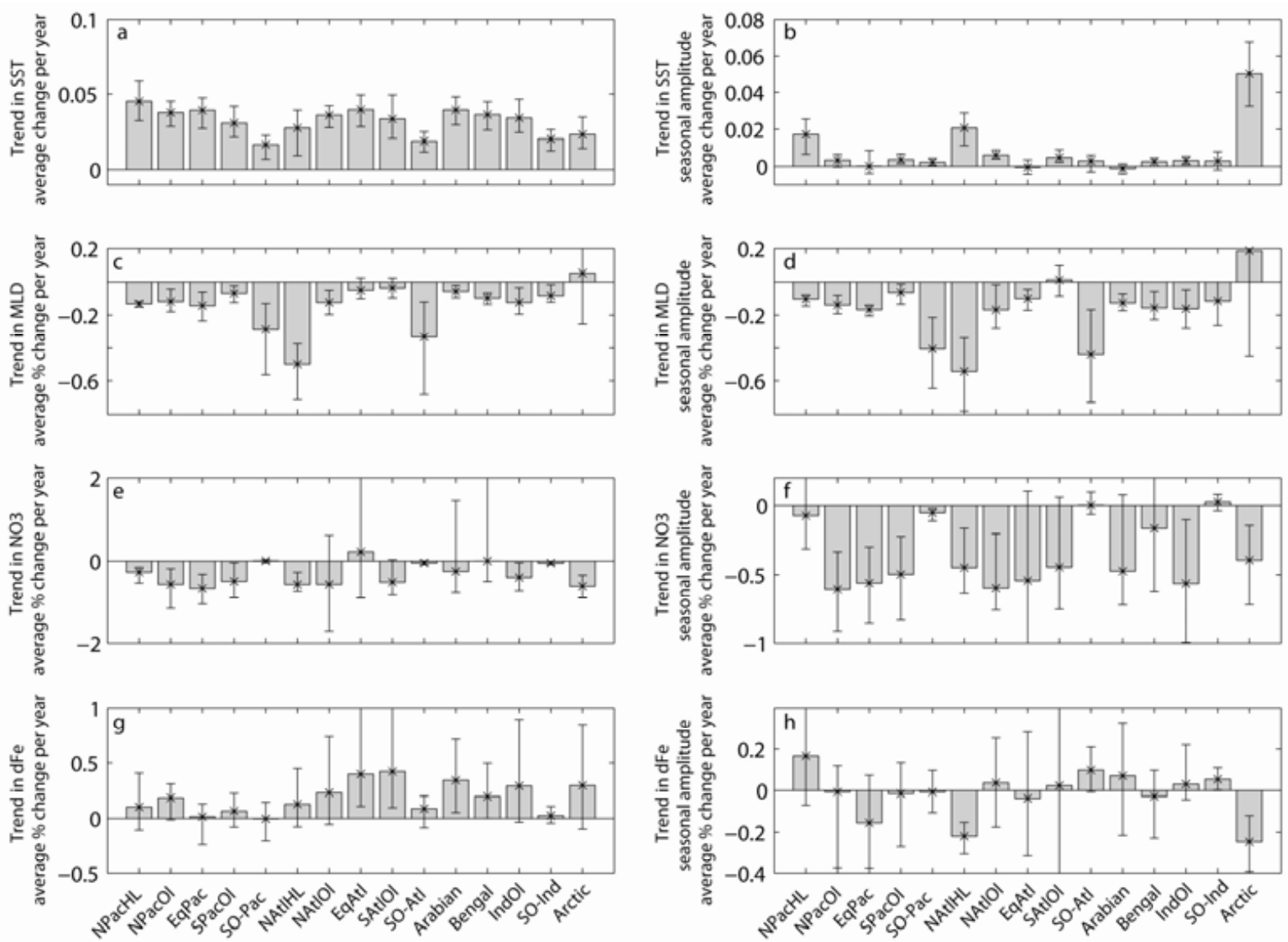

Fig. 6. Biome mean trends and standard deviations for 6 coupled models forced with IPCC AR5 scenario RCP8.5 until 2100 expressed as average \% change per year, except SST which is shown in average ${ }^{\circ} \mathrm{C}$ change per year. (a) Mean annual SST, (b) seasonal amplitude of SST, (c) mean annual MLD, (d) seasonal amplitude of MLD, (e) mean annual surface nitrate concentration, (f) seasonal amplitude of surface nitrate concentration, (g) mean annual surface dissolved iron concentration and (h) seasonal amplitude of surface dissolved iron concentration. Biome labels are the same as in Fig. 5.

phytoplankton bloom can occur. The contemporary Southern Ocean is iron limited and possibly light limited (Mitchell et al., 1991; Boyd et al., 2000). Of the models that report surface dissolved iron concentrations (GFDL, IPSL, Hadley and NOC), the consensus is that iron concentrations will increase globally (Fig. 6g), particularly in the South Atlantic. In the Southern Ocean, global warming leads to an intriguing competition between alleviation of light limitation (due to shallower MLD) on the one hand and reduced winter entrainment of nutrients on the other. The seasonal amplitude of PP increases, but the timing of peak PP advances by only $\sim 5-10$ days on average, suggesting that light limitation still occurs in winter. This suggests that alleviation of nutrient limitation (likely iron) is the dominant factor that drives the change of parts of the Southern Ocean from non-bloom regions into strongly seasonal areas.

Globally, the predominant effect of climate change on PP seasonality is the conversion of bloom regions into nonbloom regions (rather than vice versa), which is likely to have subsequent impacts on food web structure and oceanic carbon uptake. On interannual timescales, the well-known "match-mismatch" hypothesis (Cushing, 1990) states that survival of larval stages of higher trophic levels depends strongly on the timing of the phytoplankton bloom. However, on longer timescales climate change promotes the expansion of oligotrophic regions and conversion of bloom regions to non-bloom regions, resulting in a whole-scale change to the ecosystem structure. Contemporary bloom regions tend to be dominated by diatoms in early spring, before being succeeded by smaller phytoplankton, and they also support abundant fisheries, as well as being regions of high carbon export and thus often $\mathrm{CO}_{2}$ sinks. Non-bloom regions, on the other hand, are dominated by small phytoplankton and are fuelled by recycled nutrients, thus contributing little to carbon export, and they additionally support meagre higher trophic level populations. Earlier studies focusing on climate change effects on export production confirm this hypothesis, with a projected increase in the abundance of small phytoplankton 


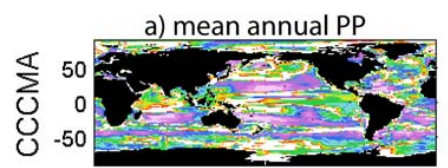

b) seasonal amplitude of PP
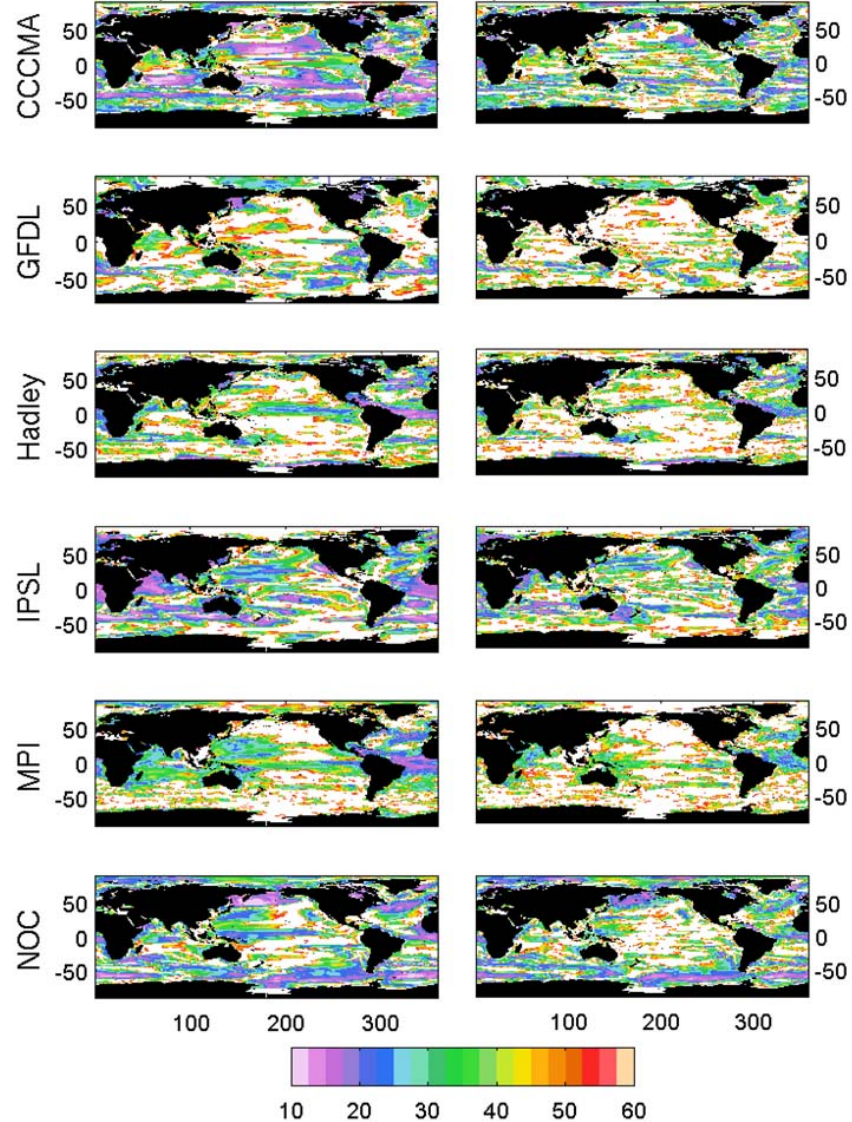

Fig. 7. Number of years of continuous data required to separate a global warming trend (RCP8.5 scenario, 2006-2100) from natural variability in time series of (a) mean annual primary production and (b) seasonal amplitude of primary production. Only points where the trend is statistically significant at the $95 \%$ level are plotted.

at the expense of diatoms, and a subsequent decrease in global carbon export (Bopp et al., 2005; Steinacher et al., 2010). The predicted pronounced reduction in the amplitude of the PP seasonal cycle would therefore have profound implications for both global fish production and the air-sea partitioning of $\mathrm{CO}_{2}$.

\subsection{Detecting climate change trends in phytoplankton phenology and seasonality}

A key aim of this study was to investigate the hypothesis that global warming may be detectable in seasonality metrics more rapidly than in other metrics (Sparks and Menzel, 2002). Previous work suggested that in order to distinguish a climate change trend from natural variability, a continuous PP record of $\sim 30-40 \mathrm{yr}$ in length was required (Henson et al., 2010). In light of the ongoing threats to a continuous ocean colour record, it behoves us to investigate whether alternative indicators of PP response to climate change are more rapidly detectable. We find however that, on average, $\sim 36 \mathrm{yr}$ of continuous data on the seasonal amplitude of PP is required to distinguish the climate change trend from natural variability. This is in contrast to PP itself which, for this emissions scenario and suite of models, requires $\sim 32 \mathrm{yr}$ of data.

Detecting changes in timing of peak PP (or timing of any other seasonally recurring event) is limited by the monthly resolution of the model output, i.e. only changes in peak PP timing of greater than 1 month are resolved. In some regions changes in peak timing far exceed 1 month by 2100 , but if shifts in the peak timing are more subtle, higher temporal resolution output will be required to detect them. One of the few in situ datasets long enough to assess trends in phytoplankton phenology, the Continuous Plankton Recorder dataset, suggests that the peak timing of dinoflagellate blooms in the North Sea has shifted earlier by $\sim 1$ month over $45 \mathrm{yr}$ (Edwards and Richardson, 2004). This trend would be at the limit of detection for the model output used here. The earth system models used here are typically run with a daily time step; however, only monthly mean output is saved due to limited storage space. Use of higher temporal resolution output would result in an increased sensitivity of phenological metrics to changing conditions and so may allow for more rapid detection of trends in seasonality. An interesting experiment would be to repeat one of the model runs analysed here, saving the output at higher temporal resolution, and investigating whether the number of years of data required to detect a climate change trend in phenological metrics was reduced.

An additional confounding factor in detecting trends in phenology is strong natural variability, whether on interannual timescales driven by local changes in forcing, or on multiyear timescales driven by basin-wide modes of variability, such as the North Atlantic Oscillation or Pacific Decadal Oscillation. As examples, the timing of phytoplankton bloom initiation was found to vary interannually by $\sim 2-6$ weeks in the North Atlantic (Henson et al., 2009), whilst the peak zooplankton abundance was observed to vary interannually by 1-3 months in a global synthesis (Mackas et al., 2012). These results (and many others) suggest that interannual variability in plankton phenology is large and of a similar magnitude to the modelled trend, which hinders the ability to distinguish the two signals. Sparks and Menzel (2002) suggested that phenological indicators are particularly sensitive indicators of climate change. However, the same properties that make phytoplankton seasonality sensitive to climate change, i.e. rapid growth and sensitivity to changes in environmental conditions, also make seasonality sensitive to natural interannual forcing. On the other hand, a deeper understanding of seasonal variability could also result in an improved ability to detect climate-change-driven trends. For example, including a statistical model of the seasonal components of a time series in the trend analysis may increase its sensitivity (e.g. Weatherhead et al., 1997). Changes in seasonality can also amplify or mask trends as shown for SST by Cohen et al. (2012), who demonstrated that the recent pause 
in increasing global temperatures is a seasonal phenomenon. Careful consideration of seasonal effects may therefore aid in detecting climate-change-driven trends. However, as shown here, analysis of phytoplankton seasonality is not necessarily an automatic shortcut to detecting climate change impacts on ocean ecosystems. Note, though, that we have made the assumption that trends in PP and PP seasonality are linear and that the residual noise follows an AR(1). Further refinements would be required to detect nonlinear trends or abrupt changes with a different autocorrelation structure, as well as determine the number of years of observations necessary for their detection.

The imperative for sustained monitoring of ocean productivity remains undiminished, and the recent loss of the ESA ocean colour instrument, MERIS, in April 2012 brings into sharp focus the possibility of a gap in the ocean colour record. At the time of writing, MODIS-Aqua is the only fully operational global ocean colour sensor still operating, and with a new instrument (on ESA's Sentinel-3 craft) not planned for launch until late 2013, the potential for a break in the ocean colour climate record looms. As demonstrated in Henson et al. (2010) and Beaulieu et al. (2013), a discontinuity in the time series could substantially increase the number of years of data required to detect a climate-change-driven trend - a delay we can ill-afford if we wish to understand the impact of climate change on ocean ecosystems.

\section{Supplementary material related to this article is available online at: http://www.biogeosciences.net/10/ 4357/2013/bg-10-4357-2013-supplement.pdf.}

Acknowledgements. We acknowledge the World Climate Research Programme's Working Group on Coupled Modelling, which is responsible for CMIP, and we thank the climate modelling groups (listed in Table 1 of this paper) for producing and making available their model output. For CMIP the US Department of Energy's Program for Climate Model Diagnosis and Intercomparison provides coordinating support and led development of software infrastructure in partnership with the Global Organization for Earth System Science Portals. This work was supported by NERC grant NE/G013055/1 to SAH.

Edited by: L. Bopp

\section{References}

Beaulieu, C., Henson, S. A., Sarmiento, Jorge L., Dunne, J. P., Doney, S. C., Rykaczewski, R. R., and Bopp, L.: Factors challenging our ability to detect long-term trends in ocean chlorophyll, Biogeosciences, 10, 2711-2724, doi:10.5194/bg-10-27112013, 2013.
Behrenfeld, M. J. and Falkowski, P. G.: Photosynthetic rates derived from satellite-based chlorophyll concentration, Limnol. Oceanogr., 42, 1-20, 1997.

Bopp, L., Monfray, P., Aumont, O., Dufresne, J. L., Le Treut, H., Madec, G., Terray, L., and Orr, J. C.: Potential impact of climate change on marine export production, Global Biogeochem. Cy., 15, 81-99, doi:10.1029/1999gb001256, 2001.

Bopp, L., Aumont, O., Cadule, P., Alvain, S., and Gehlen, M.: Response of diatoms distribution to global warming and potential implications: A global model study, Geophys. Res. Lett., 32, L19606, doi:10.1029/2005GL023653, 2005.

Boyd, P. W., Watson, A. J., Law, C. S., Abraham, E. R., Trull, T., Murdoch, R., Bakker, D. C. E., Bowie, A. R., Buesseler, K. O., Chang, H., Charette, M., Croot, P., Downing, K., Frew, R., Gall, M., Hadfield, M., Hall, J., Harvey, M., Jameson, G., LaRoche, J., Liddicoat, M., Ling, R., Maldonado, M. T., McKay, R. M., Nodder, S., Pickmere, S., Pridmore, R., Rintoul, S., Safi, K., Sutton, P., Strzepek, R., Tanneberger, K., Turner, S., Waite, A., and Zeldis, J.: A mesoscale phytoplankton bloom in the polar Southern Ocean stimulated by iron fertilization, Nature, 407, 695-702, doi:10.1038/35037500, 2000.

Burrows, M. T., Schoeman, D. S., Buckley, L. B., Moore, P., Poloczanska, E. S., Brander, K. M., Brown, C., Bruno, J. F., Duarte, C. M., Halpern, B. S., Holding, J., Kappel, C. V., Kiessling, W., O'Connor, M. I., Pandolfi, J. M., Parmesan, C., Schwing, F. B., Sydeman, W. J., and Richardson, A. J.: The Pace of Shifting Climate in Marine and Terrestrial Ecosystems, Science, 334, 652-655, doi:10.1126/science.1210288, 2011.

Cohen, J. L., Furtado, J. C., Barlow, M., Alexeev, V. A., and Cherry, J. E.: Asymmetric seasonal temperature trends, Geophys. Res. Lett., 39, L04705, doi:10.1029/2011g1050582, 2012.

Cole, H. S., Henson, S. A., Martin, A. P., and Yool, A.: Mind the gap: The impact of missing data on the calculation of phytoplankton phenology metrics, J. Geophys. Res., 117, C8, doi:10.1029/2012JC008249, 2012.

Collins, W. J., Bellouin, N., Doutriaux-Boucher, M., Gedney, N., Halloran, P., Hinton, T., Hughes, J., Jones, C. D., Joshi, M., Liddicoat, S., Martin, G., O’Connor, F., Rae, J., Senior, C., Sitch, S., Totterdell, I., Wiltshire, A., and Woodward, S.: Development and evaluation of an Earth-System model-HadGEM2, Geosci. Model Develop., 4, 1051-1075, doi:10.5194/gmd-4-1051-2011, 2011.

Cushing, D. H.: Plankton production and year-class strength in fish populations - an update of the match mismatch hypothesis, Adv. Mar. Biol., 26, 249-293, doi:10.1016/s0065-2881(08)60202-3, 1990.

Doney, S. C.: Oceanography - Plankton in a warmer world, Nature, 444, 695-696, doi:10.1038/444695a, 2006.

Edwards, M. and Richardson, A. J.: Impact of climate change on marine pelagic phenology and trophic mismatch, Nature, 430 881-884, doi:10.1038/nature02808, 2004.

Friedrichs, M. A. M., Carr, M.-E., Barber, R. T., Scardi, M., Antoine, D., Armstrong, R. A., Asanuma, I., Behrenfeld, M. J., Buitenhuis, E. T., Chai, F., Christian, J. R., Ciotti, A. M., Doney, S. C., Dowell, M., Dunne, J., Gentili, B., Gregg, W., Hoepffner, N., Ishizaka, J., Kameda, T., Lima, I., Marra, J., Melin, F., Moore, J. K., Morel, A., O’Malley, R. T., O'Reilly, J., Saba, V. S., Schmeltz, M., Smyth, T. J., Tjiputra, J., Waters, K., Westberry, T. K., and Winguth, A.: Assessing the uncertainties of model estimates of primary productivity in the tropical Pacific Ocean, 
J. Mar. Sys., 76, 113-133, doi:10.1016/j.jmarsys.2008.05.010, 2009.

Hasselmann K.: Stochastic climate models, Part 1: Theory, Tellus, 28: 473-485, 1976.

Henson, S. A., Dunne, J. P., and Sarmiento, J. L.: Decadal variability in North Atlantic phytoplankton blooms, J. Geophys. Res., 114, C04013, doi:10.1029/2008jc005139, 2009.

Henson, S. A., Sarmiento, J. L., Dunne, J. P., Bopp, L., Lima, I., Doney, S. C., John, J., and Beaulieu, C.: Detection of anthropogenic climate change in satellite records of ocean chlorophyll and productivity, Biogeosciences, 7, 621-640, doi:10.5194/bg-7621-2010, 2010.

Henson, S. A., Lampitt, R., and Johns, D.: Variability in phytoplankton community structure in response to the North Atlantic Oscillation and implications for organic carbon flux, Limnol. Oceanogr., 57, 1591-1601, 2012.

Ji, R. B., Edwards, M., Mackas, D. L., Runge, J. A., and Thomas, A. C.: Marine plankton phenology and life history in a changing climate: current research and future directions, J. Plankton Res., 32, 1355-1368, doi:10.1093/plankt/fbq062, 2010.

Kahru, M., Brotas, V., Manzano-Sarabia, M., and Mitchell, B. G.: Are phytoplankton blooms occurring earlier in the Arctic?, Glob. Change Biol., 17, 1733-1739, 2011.

Koeller, P., Fuentes-Yaco, C., Platt, T., Sathyendranath, S., Richards, A., Ouellet, P., Orr, D., Skuladottir, U., Wieland, K., Savard, L., and Aschan, M.: Basin-Scale Coherence in Phenology of Shrimps and Phytoplankton in the North Atlantic Ocean, Science, 324, 791-793, doi:10.1126/science.1170987, 2009.

Lutz, M. J., Caldeira, K., Dunbar, R. B., and Behrenfeld, M. J.: Seasonal rhythms of net primary production and particulate organic carbon flux to depth describe the efficiency of biological pump in the global ocean, J. Geophys. Res., 112, C10011, doi:10.1029/2006jc003706, 2007.

Mackas, D. L., Greve, W., Edwards, M., Chiba, S., Tadokoro, K., Eloire, D., Mazzocchi, M. G., Batten, S., Richardson, A. J., Johnson, C., Head, E., Conversi, A., and Peluso, T.: Changing zooplankton seasonality in a changing ocean: Comparing time series of zooplankton phenology, Prog. Oceanogr., 97, 31-62, doi:10.1016/j.pocean.2011.11.005, 2012.

Mitchell, B. G., Brody, E. A., Holmhansen, O., McClain, C., and Bishop, J.: Light limitation of phytoplankton biomass and macronutrient utilization in the Southern-Ocean, Limnol. Oceanogr., 36, 1662-1677, 1991.

Moss, R. H., Edmonds, J. A., Hibbard, K. A., Manning, M. R., Rose, S. K., van Vuuren, D. P., Carter, T. R., Emori, S., Kainuma, M., Kram, T., Meehl, G. A., Mitchell, J. F. B., Nakicenovic, N., Riahi, K., Smith, S. J., Stouffer, R. J., Thomson, A. M., Weyant, J. P., and Wilbanks, T. J.: The next generation of scenarios for climate change research and assessment, Nature, 463, 747-756, doi:10.1038/nature08823, 2010.

Myneni, R. B., Keeling, C. D., Tucker, C. J., Asrar, G., and Nemani, R. R.: Increased plant growth in the northern high latitudes from 1981 to 1991 , Nature, 386, 698-702, doi:10.1038/386698a0, 1997.

Nakicenovic, N. and Swart, R.: Special Report on Emissions Scenarios: A special report of Working Group III of the Intergovernmental Panel on Climate Change, Cambridge University Press, Cambridge, 2000.
Parmesan, C.: Influences of species, latitudes and methodologies on estimates of phenological response to global warming, Glob. Change Biol., 13, 1860-1872, doi:10.1111/j.13652486.2007.01404.x, 2007.

Platt, T., Fuentes-Yaco, C., and Frank, K. T.: Spring algal bloom and larval fish survival, Nature, 423, 398-399, doi:10.1038/423398b, 2003.

Platt, T., White, G. N., Zhai, L., Sathyendranath, S., and Roy, S.: The phenology of phytoplankton blooms: Ecosystem indicators from remote sensing, Ecol. Modell., 220, 3057-3069, 2009.

Polovina, J. J., Dunne, J. P., Woodworth, P. A., and Howell, E. A.: Projected expansion of the subtropical biome and contraction of the temperate and equatorial upwelling biomes in the North Pacific under global warming, ICES J. Mar. Sci., 68, 986-995, doi:10.1093/icesjms/fsq198, 2011.

Racault, M. F., Le Quere, C., Buitenhuis, E., Sathyendranath, S., and Platt, T.: Phytoplankton phenology in the global ocean, Ecol. Indic., 14, 152-163, doi:10.1016/j.ecolind.2011.07.010, 2012.

Rogelj, J., Meinshausen, M., and Knutti, R.: Global warming under old and new scenarios using IPCC climate sensitivity range estimates, Nat. Clim. Change, 2, 248-253, doi:10.1038/NCLIMATE1385, 2012.

Saba, V. S., Friedrichs, M. A. M., Carr, M.-E., Antoine, D., Armstrong, R. A., Asanuma, I., Aumont, O., Bates, N. R., Behrenfeld, M. J., Bennington, V., Bopp, L., Bruggeman, J., Buitenhuis, E. T., Church, M. J., Ciotti, A. M., Doney, S. C., Dowell, M., Dunne, J., Dutkiewicz, S., Gregg, W., Hoepffner, N., Hyde, K. J. W., Ishizaka, J., Kameda, T., Karl, D. M., Lima, I., Lomas, M.W., Marra, J., McKinley, G. A., MÈlin, F., Moore, J. K., Morel, A., O’Reilly, J., Salihoglu, B., Scardi, M., Smyth, T. J., Tang, S., Tjiputra, J., Uitz, J., Vichi, M., Waters, K., Westberry, T. K., and Yool, A.: Challenges of modeling depthintegrated marine primary productivity over multiple decades: A case study at BATS and HOT, Global Biogeochem. Cy., 24, GB3020, doi:10.1029/2009GB003655, 2010.

Sapiano, M., Brown, C.W., Schollaert Uz, S., and Vargas, M.: Establishing a global climatology of marine phytoplankton phenological characteristics, J. Geophys. Res., 117, C08026, doi:10.1029/2012JC007958, 2012.

Sarmiento, J. L., Slater, R., Barber, R., Bopp, L., Doney, S. C., Hirst, A. C., Kleypas, J., Matear, R., Mikolajewicz, U., Monfray, P., Soldatov, V., Spall, S. A., and Stouffer, R.: Response of ocean ecosystems to climate warming, Global Biogeochem. Cy., 18, GB3003, doi:10.1029/2003gb002134, 2004.

Sarmiento, J. L., Slater, R. D., Dunne, J., Gnanadesikan, A., and Hiscock, M. R.: Efficiency of small scale carbon mitigation by patch iron fertilization, Biogeosciences, 7, 3593-3624, doi:10.5194/bg-7-3593-2010, 2010.

Sasaoka, K., Chiba, S., and Saino, T.: Climatic forcing and phytoplankton phenology over the subarctic North Pacific from 1998 to 2006, as observed from ocean color data, Geophys. Res. Lett., 38, L15609, doi:10.1029/2011g1048299, 2011.

Schneider, B., Bopp, L., Gehlen, M., Segschneider, J., Frölicher, T. L., Cadule, P., Friedlingstein, P., Doney, S. C., Behrenfeld, M. J., and Joos, F.: Climate-induced interannual variability of marine primary and export production in three global coupled climate carbon cycle models, Biogeosciences, 5, 597-614, doi:10.5194/bg-5-597-2008, 2008. 
Seferian, R., Bopp, L., Gehlen, M., Orr, J. C., Ethe, C., Cadule, P., Aumont, O., Salas y Melia, D., Voldoire, A., and Madec, G.: Skill assessment of three earth system models with common marine biogeochemistry, Clim. Dynam., 40, 2549-2573, doi:10.1007/s00382-012-1362-8, 2013.

Sparks, T. H. and Menzel, A.: Observed changes in seasons: An overview, Int. J. Climatol., 22, 1715-1725, doi:10.1002/joc.821, 2002.

Steinacher, M., Joos, F., Frölicher, T. L., Bopp, L., Cadule, P., Cocco, V., Doney, S. C., Gehlen, M., Lindsay, K., Moore, J. K., Schneider, B., and Segschneider, J.: Projected 21st century decrease in marine productivity: a multi-model analysis, Biogeosciences, 7, 979-1005, doi:10.5194/bg-7-979-2010, 2010.

Steinberg, D. K., Lomas, M. W., and Cope, J. S.: Long-term increase in mesozooplankton biomass in the Sargasso Sea: Linkage to climate and implications for food web dynamics and biogeochemical cycling, Global Biogeochem. Cy., 26, GB1004, doi:10.1029/2010gb004026, 2012.

Stone, D. A., Weaver, A. J., and Stouffer, R. J.: Projection of climate change onto modes of atmospheric variability, J. Clim., 14, 3551-3565, doi:10.1175/15200442(2001)014<3551:poccom>2.0.co;2, 2001.

Taylor, K. E.: Summarizing multiple aspects of model performance in a single diagram, J. Geophys. Res., 106, 7183-7192, doi:10.1029/2000jd900719, 2001.

Taylor, K. E., Stouffer, R., and Meehl, G.: A summary of the CMIP5 experiment design, Bull. Am. Meteor. Soc., 93, 485-498, doi:10.1175/BAMS-D-11-00094.1, 2012.
Thomalla, S., Fauchereau, N., Monteiro, P., and Swart, S.: Regional scale characteristics of the seasonal cycle of chlorophyll in the Southern Ocean, Biogeosciences, 8, 2849-2866, doi:10.5194/bg8-2849-2011, 2011.

Walther, G. R., Post, E., Convey, P., Menzel, A., Parmesan, C., Beebee, T. J. C., Fromentin, J. M., Hoegh-Guldberg, O., and Bairlein, F.: Ecological responses to recent climate change, Nature, 416, 389-395, doi:10.1038/416389a, 2002.

Weatherhead, E. C., Reinsel, G. C., Tiao, G. C., Meng, X. L., Choi, D. S., Cheang, W. K., Keller, T., DeLuisi, J., Wuebbles, D. J., Kerr, J. B., Miller, A. J., Oltmans, S. J., and Frederick, J. E.: Factors affecting the detection of trends: Statistical considerations and applications to environmental data, J. Geophys. Res., 103, 17149-17161, doi:10.1029/98jd00995, 1998.

Yool, A., Popova, E. E., and Anderson, T. R.: Medusa-1.0: a new intermediate complexity plankton ecosystem model for the global domain, Geosci. Model Dev., 4, 381-417, doi:10.5194/gmd-4381-2011, 2011.

Zahariev, K., Christian, J. R., and Denman, K. L.: Preindustrial, historical, and fertilization simulations using a global ocean carbon model with new parameterizations of iron limitation, calcification, and N-2 fixation, Prog. Oceanogr., 77, 56-82, doi:10.1016/j.pocean.2008.01.007, 2008.

Zhai, L., Platt, T., Tang, C., Sathyendranath, S., Fuentes-Yaco, C., Devred, E., and Wu, Y. S.: Seasonal and geographic variations in phytoplankton losses from the mixed layer on the Northwest Atlantic Shelf, J. Mar. Sys., 80, 36-46, 2010. 